\title{
MOTIVATIONS FOR THE TRAINING EFFORT OF ROMANIAN MASTERS ATHLETES
}

\author{
Daniela BABA ${ }^{1 *}$, Lorand BALINT ${ }^{1}$ \\ ${ }^{1}$ Transylvania University, Faculty of Physical Education and Mountain Sports, Braşov, Romania \\ *Corresponding author: daniela.baba@unitbv.ro
}

https://doi.org/10.35189/dpeskj.2021.60.3.7

\begin{abstract}
The aim of this study was to investigate the motivations of Romanian Masters athletes to train for endurance running in order to participate in half-marathon competitions. The research method used was the survey. This tool consisted of a questionnaire that was purposely developed for the present research. Out of the 111 experienced respondents practising running for 13 years on average, $61.8 \%$ are men and $38.2 \%$ are women. The results are different and are mainly focused on reaching a state of well-being (67\%) for both men (67.2\%) and women (66.7\%); there are significant differences between the 35-44 and 55+ age categories $(t=2.776, p<$ 0.01). This motivation has contributed to maintaining and improving physical performance with aging. Women are more motivated than men to run for health benefits. In conclusion, we believe that paying attention to motivation is important in terms of encouraging people of all ages to play outdoor sports, promoting a healthy lifestyle based on exercise and managing grassroots sport. The Masters athlete is a rich source of information regarding a person's ability to maintain maximum physical performance and physiological function as they get older. The impressive capacity for physical performance and physiological functioning makes Masters athletes a model for society.
\end{abstract}

Keywords: motivation, Masters athletes' training, half-marathon.

\section{Introduction}

People seek opportunities for challenges and accomplishments in their leisure hobbies, look for enthusiasm, pleasant experiences and, in some cases, take an intentional risk that is under their control when performing these activities. The self-determination theory (Deci \& Ryan, 1985) regarding intrinsic and extrinsic motivations explains the importance of psychological needs for the structure of motivation for action in various areas of life, including sport (Poczta \& Malchrowicz-Mosko, 2018).

We expected to identify, both in the studied literature and among Masters athletes, the motivations for performing a rather challenging but enjoyable sports activity.

Motivation refers to the fact that behavioural acts do not take place unintentionally, they are always based on internal reasons that give an impulse to the activity and support it energetically (Epuran et al., 2008).

Studying the endurance running motivation of Masters athletes is a topic of interest for some authors. Examples of articles: Modern Running Events in Sustainable Development - More than Just Taking Care of Health and Physical Condition (Poznan Half Marathon Case Study) (Poczta \& Malchrowicz-Mośko, 2018); Who Participates in Running Events? SocioDemographic Characteristics, Psychosocial Factors and Barriers as Correlates of NonParticipation: A Pilot Study in Belgium (Van Dyck et al., 2017); Running as a Form of Therapy Socio-Psychological Functions of Mass Running Events for Men and Women (MalchrowiczMośk \& Poczta, 2018). 
The authors of the mentioned articles are mainly concerned with the sociodemographic characteristics and suggest that the motivational aspects and psychological features of Masters athletes play an important role in participating in endurance events, specifically half-marathon races, which is an increasingly popular sport worldwide (Nikolaidis et al., 2019).

Although most Masters athletes generally engage in endurance running to improve their physical fitness, their main motivation to participate in sports events such as the half-marathon seems to be the personal challenge (Summers et al., 1982; Malchrowicz-Mośko et al., 2018).

Nowadays, physical activity is extremely important in the sociocultural dimension and reflects the need for a modern, current lifestyle (Poczta \& Malchrowicz-Mośko, 2018). Lack of physical activity has become a major concern among the population, being associated with the diseases of civilization. Endurance running has great health benefits. It has been found that it reduces cardiovascular diseases, stroke, several types of cancer, depression (Nikolaidis et al., 2019) and strengthens the musculoskeletal system, body composition and psychological wellbeing by inducing a state of relaxation (Menheere et al., 2020). Running relaxes, brings optimism and zest for life, according to Dumitrescu (2019). These health benefits of endurance running are one of the reasons for the large participation of Masters athletes in running events and the increased scientific interest in this category of athletes.

Doyenart et al. (2020) state in their article that there is a relationship between mental health and the physical activity of recreational runners. The authors have shown that running over different distances can alter the level of anxiety, stress and the mood of athletes. Psychophysiological changes were studied in Masters athletes at the end of the half-marathon and an increase in their level of happiness (25\%) and self-esteem (40\%) was found. The study involved measurements of physiological parameters (heart rate, energy expenditure) and assessments of mental health (stress, anxiety, self-esteem, happiness). The conclusion is that half-marathon training can lead to increased happiness and self-esteem in runners.

Poczta and Malchrowicz-Mośk (2018) have shown that there are significant differences between the motivations of urban and rural Masters athletes as follows: Masters athletes in urban areas say they run to have fun, to test themselves, while those in rural areas are more motivated by emotional experiences and the atmosphere created by the event.

Malchrowicz-Mośk and Poczta (2018) studied the reasons of two groups (men and women) for participating in a half-marathon event and noted that the motives underlying their participation were in line with the four basic guidelines: social orientation, experience orientation, factual orientation and result orientation. A major difference between the men and women who took part in the above study consisted in the fact that the desire to escape from everyday life was more important for women than men. The desire to win was not important for either men or women. Both groups said that the most important thing for them was the need to experience strong emotions related to participation, the desire for unity and social integrity and the pleasure of testing their physical and mental limits.

Masters et al. (1993) created a tool for assessing the motivations of endurance runners, namely the Motivations of Marathoners Scales (MOMS), which consists of 56 items distributed across 9 scales focused on: health, weight concern, self-esteem, meaning of life, psychological coping, affiliation, recognition, competition, personal goal achievement. This tool for motivation assessment is still used in some studies. 
Malchrowicz-Mośk et al. (2020) used the MOMS to investigate the motivations of novice runners over the age of 36 years on the basis of their sociodemographic profiles. The results of the study showed that men's motivations to run were mostly related to competition, while women's motivations were related to belonging, psychological coping and meaning of life.

Purpose of the study: researching the type of motivation and identifying the training regimen of Masters athletes.

Hypothesis. We assume that, following the research conducted in the form of a questionnaire applied to all samples involved in the study (men and women, both athletes and amateurs), we will find that their motivations to practise endurance running are similar. We start from the premise that their motivational intention would be to obtain a state of well-being, the need to socialise, to gain prestige in groups/society and to maintain health.

\section{Methodology}

\section{Participants}

The study involved 111 Masters athletes, of which $38.2 \%$ were women and $61.8 \%$ were men. Participants were informed about the significance of the study in the introductory part of the questionnaire and were asked to provide the required information. There were no criteria for excluding questionnaires and therefore all were accepted.

\section{Instruments}

The questionnaire developed by the authors of this study included the following dimensions:

- Sociodemographic data (gender, age, education level, place of residence, marital status);

- Personal data about sports activity (having a personal trainer, health issues, membership in a sports club, past athletic performance, participation in national and/or international competitions, number of training sessions per week);

- Motivations for running;

- Perception of running-induced changes (perceived improvement of some aspects related to sleep quality, body weight, physical immunity and diet).

\section{Procedure}

\section{Sampling procedure}

2020 was a non-competitive year due to the COVID-19 pandemic, so any attempt to select a random sample was pointless. The authors of this study contacted the organizers of a 2019 half-marathon and obtained a list of Masters participants. Out of the list of 134 Masters participants, 111 answered the call to respond to the questionnaire items, which means a percentage of $83 \%$. We can say that the sampling method involved sampling at the place of consumption, even if the data collection was done long after the half-marathon. Sampling at the place of consumption is a non-randomised type of sampling, therefore we cannot generalise the sample data to the entire population. We mention that the study did not collect identification data of the participants (name, address, e-mail address, etc.), the information being anonymous. 
Informed consent was obtained automatically when participants voluntarily completed the questionnaire. The responses were received electronically and physically, in writing.

2. Statistical analysis

Analyses were performed in SPSS 20. Descriptive Student's t-tests for independent samples were used. We mention that the normality of distributions was assumed but not tested.

Supplementary material: SPSS data file of the study and 111 questionnaires in letter format

\section{Results}

Running events are usually by age group, with a range of 5 years $(35-39,40-44,45-49,50$ $54,55-59,+60)$. Participation rate and performance level vary according to the age group (Nikolaidis et al., 2018).

- Results for the demographic profile of the sample

Out of the 111 respondents, $61.8 \%$ are men and $38.2 \%$ are women. The age distribution is as follows: $34.5 \%$ between 35 and 39 years, $16.4 \%$ between 40 and 44 years, $18.2 \%$ between 45 and 49 years, $13.6 \%$ between 50 and 54 years, $5.5 \%$ between 55 and 59 years and $11.8 \%$ over 60 years (Table 1). The gender-age contingency table shows equal distributions for the second, third and fifth age ranges and an overrepresentation of men in the first, fourth and last age ranges.

Table 1. Distribution of athletes by age category

\begin{tabular}{lcc}
\hline \multirow{2}{*}{ Age categories } & \multicolumn{2}{c}{ Gender } \\
\cline { 2 - 3 } 35-39 years & $65.8 \%$ & Women \\
\hline 40-44 years & $50.0 \%$ & $34.2 \%$ \\
45-49 years & $50.0 \%$ & $50.0 \%$ \\
50-54 years & $73.3 \%$ & $50.0 \%$ \\
55-59 years & $50.0 \%$ & $56.7 \%$ \\
60 years and over & $76.9 \%$ & $23.1 \%$ \\
Mean & $61.8 \%$ & $38.2 \%$ \\
\hline
\end{tabular}

The distribution according to the level of education is disproportionately biased towards those with a higher level of education, women being slightly overrepresented in the sample (Table 2).

Table 2. Distribution of athletes by level of education

\begin{tabular}{lccc}
\hline \multirow{2}{*}{ Level of education } & \multicolumn{2}{c}{ Gender } & \\
\cline { 2 - 3 } & Men & Women & Mean \\
\hline Secondary & $13.4 \%$ & $11.9 \%$ & $12.7 \%$ \\
University & $86.6 \%$ & $88.1 \%$ & $87.4 \%$ \\
\hline
\end{tabular}

The distribution by area of residence is disproportionately biased towards those in urban areas, with men slightly overrepresented in the sample (Table 3). 
Table 3. Distribution of athletes by area of residence

\begin{tabular}{lccc}
\hline \multirow{2}{*}{ Area of residence } & \multicolumn{2}{c}{ Gender } & \\
\cline { 2 - 3 } & Men & Women & Mean \\
\hline Urban & $89.6 \%$ & $85.7 \%$ & $87.7 \%$ \\
Rural & $10.4 \%$ & $14.3 \%$ & $12.4 \%$ \\
\hline
\end{tabular}

\section{- Results for motivation}

The respondents' motivations to participate in running competitions are shown in Table 4. We received 170 responses from 106 participants, so an average of 1.6 responses per participant. We classified the responses according to question 13 ("What motivated you to run?") into four types of motivations as follows: affiliation, well-being, recognition and health.

Table 4. Motivations of Masters athletes

\begin{tabular}{lc}
\hline \multicolumn{1}{c}{ Motivations } & Percentage of cases \\
\hline q13 affiliation & $45.3 \%$ \\
q13 well-being & $67.0 \%$ \\
q13 recognition & $28.3 \%$ \\
q13 health & $19.8 \%$ \\
\hline
\end{tabular}

Figure 1 shows the differences between age categories in terms of athletes' motivations. Affiliation is the most important for the 45-54 age segment and the least important for those over 55, with no significant differences in averages $(\mathrm{t}=1.42, \mathrm{p}>0.05)$. Well-being is the most important reason for all three age categories $(35-44,45-54,55+)$, but one can observe the strictly increasing distribution with age, with significant differences between the first age category (35-44 years) and the last one (55 years and over) $(\mathrm{t}=2.776, \mathrm{p}<0.01)$. Recognition is the third reason, being the most important for the first age category and the least important for the second category, without significant differences in averages $(t=1.77, p>0.05)$. Overall, health is the last reason why athletes run, being the most important for the 45-54 age category and the least important for the category of people aged 55 and over, without significant differences in averages $(t=1.94, \mathrm{p}>0.05)$. 


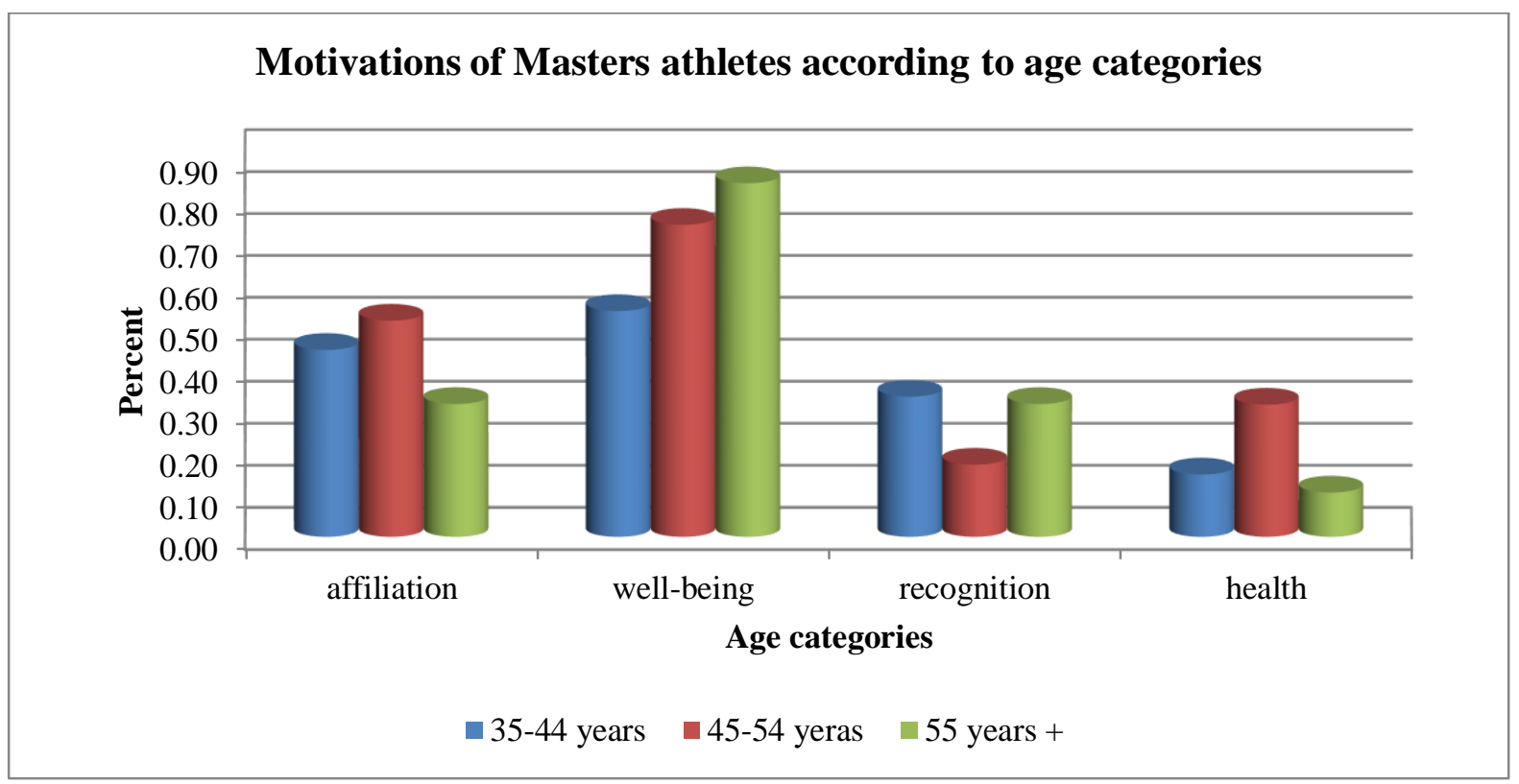

Figure 1. Motivations of Masters athletes according to age categories

The motivation-based distribution of men and women is shown in Table 5. Men are overrepresented in terms of motivations for affiliation, well-being and recognition, while women have motivations for health. All four Student Tests for Equality Percentage reveal insignificant differences between men and women.

Table 5. Distribution of motivations by groups of men and women

\begin{tabular}{|c|c|c|c|c|c|}
\hline \multirow[b]{2}{*}{ Age categories } & \multicolumn{2}{|c|}{ Gender } & Levene's Test for & \multirow{2}{*}{\multicolumn{2}{|c|}{$\begin{array}{l}\text { Student's t-Test for } \\
\text { Equality of Means }\end{array}$}} \\
\hline & Men & Women & Equality of Variances & & \\
\hline q13 affiliation & $46.9 \%$ & $42.9 \%$ & $\mathrm{p}=0.627$ & $t=0.262$ & $p>0.05$ \\
\hline q13 well-being & $67.2 \%$ & $66.7 \%$ & $\mathrm{p}=0.800$ & $t=0.160$ & $\mathrm{p}>0.05$ \\
\hline q13 recognition & $32.8 \%$ & $21.4 \%$ & $p=0.146$ & $\mathrm{t}=1.200$ & $\mathrm{p}>0.05$ \\
\hline q13 health & $17.2 \%$ & $23.8 \%$ & $\mathrm{p}=0.030$ & $\mathrm{t}=-0.900$ & $\mathrm{p}>0.05$ \\
\hline
\end{tabular}

The distribution of elite athletes is shown in Table 6. These athletes are overrepresented in three of the four categories of motivations, which indicates that they are more motivated than recreational runners. All four Student Tests for Equality Percentage revealed insignificant differences between elite athletes and other runners.

Table 6. Distribution of motivations for elite athletes

\begin{tabular}{|c|c|c|c|c|c|}
\hline \multirow[t]{2}{*}{ Age categories } & \multicolumn{2}{|c|}{$\begin{array}{l}\text { Have you been an } \\
\text { elite athlete? }\end{array}$} & \multirow[t]{2}{*}{$\begin{array}{c}\text { Levene's Test for } \\
\text { Equality of Variances }\end{array}$} & \multicolumn{2}{|c|}{$\begin{array}{l}\text { Student's t-Test for } \\
\text { Equality of Means }\end{array}$} \\
\hline & No & Yes & & & \\
\hline q13 affiliation & $44.7 \%$ & $46.7 \%$ & $\mathrm{p}=0.627$ & $t=0.286$ & $p>0.05$ \\
\hline q13 well-being & $67.1 \%$ & $66.7 \%$ & $\mathrm{p}=0.800$ & $\mathrm{t}=-0.125$ & $p>0.05$ \\
\hline q13 recognition & $26.3 \%$ & $33.3 \%$ & $\mathrm{p}=0.146$ & $\mathrm{t}=0.794$ & $\mathrm{p}>0.05$ \\
\hline q13 health & $17.1 \%$ & $26.7 \%$ & $\mathrm{p}=0.030$ & $\mathrm{t}=1.082$ & $\mathrm{p}>0.05$ \\
\hline
\end{tabular}




\section{- Results for sports activity}

\section{Experience}

Responses to question 1, "How long have you been practising running?", revealed a running experience of 13 years on average with a standard deviation of 12 years. The mean and standard deviation of the running period for each age category are shown in Table 7.

Table 7. Years of running experience

\begin{tabular}{lcc}
\hline \multicolumn{1}{c}{ Age range } & Mean & Std. Deviation \\
\hline 35-39 years & 7.180 & 4.465 \\
40-44 years & 8.280 & 7.226 \\
45-49 years & 16.050 & 12.927 \\
50-54 years & 13.270 & 8.181 \\
55-59 years & 35.170 & 11.822 \\
60 years and over & 23.620 & 18.505 \\
\hline
\end{tabular}

Responses to question 3, "Have you been an elite athlete?", show that $28 \%$ of participants are or have been elite athletes, with a slight overrepresentation of men (32\% versus $24 \%$ ). Most elite athletes are aged between 45-49 and 55-59. They have been practising running for 24 years on average with a standard deviation of 15 years, while nonelite athletes have an average running experience of 9 years with a standard deviation of 8 years.

\section{Training sessions}

To highlight the extent to which Masters athletes train weekly, this scale was measured with the open-ended question 5 ("What is your training plan?"). Then, the responses were recoded so that each day of the week was divided into four categories of training: high effort $(>12 \mathrm{~km}$ running), medium effort $(8-10 \mathrm{~km})$, low effort $(<8 \mathrm{~km})$, rest. Although the recoding can be considered subjective, the selection of free responses given by the four categories was consistent. The decreasing daily averages for each type of effort are shown in Table 8.

Table 8. Decreasing daily averages for each type of effort

\begin{tabular}{|c|c|c|c|c|c|c|c|}
\hline Day & $\begin{array}{l}\text { Mean } \\
\text { High } \\
\text { effort }\end{array}$ & Day & $\begin{array}{c}\text { Mean } \\
\text { Medium } \\
\text { effort }\end{array}$ & Day & $\begin{array}{l}\text { Mean } \\
\text { Low } \\
\text { effort }\end{array}$ & Day & $\frac{\text { Mean }}{\text { Break }}$ \\
\hline Saturday & .47 & Wednesday & .32 & Wednesday & .25 & Sunday & .42 \\
\hline Thursday & .32 & Friday & .30 & Monday & .24 & Monday & .26 \\
\hline Tuesday & .28 & Tuesday & .30 & Tuesday & .21 & Thursday & .26 \\
\hline Sunday & .26 & Monday & .25 & Friday & .20 & Friday & .25 \\
\hline Monday & .22 & Thursday & .23 & Saturday & .20 & Wednesday & .21 \\
\hline Wednesday & .22 & Saturday & .16 & Thursday & .17 & Tuesday & .19 \\
\hline Friday & .21 & Sunday & .16 & Sunday & .15 & Saturday & .17 \\
\hline
\end{tabular}

Another type of analysis shows how many days on average athletes dedicate to each type of effort and rest breaks.

Tables 9, 10 and 11 highlight the distribution by gender, age category and performance level of athletes. Thus, men engage in higher levels of effort 2.29 days a week compared to women, who have higher effort training sessions 1.46 days a week, the difference being significant $(\mathrm{t}=$ $2.53, \mathrm{p}<0.05)$. Women have more medium effort training sessions than men, the difference 
being insignificant $(\mathrm{t}=1.337, \mathrm{p}>0.05)$. Men have more lower effort training sessions than women, the difference being insignificant $(t=0.378, \mathrm{p}>0.05)$. Women take more days off than men, the difference being insignificant $(t=1.915, \mathrm{p}>0.05)$.

Elite athletes engage in higher effort sessions 2.23 days a week compared to recreational runners, who engage in high effort training sessions only 1.88 days a week, the difference being insignificant $(\mathrm{t}=0.93, \mathrm{p}>0.05)$. Elite athletes have more medium effort sessions than recreational runners, the difference being insignificant $(t=0.72, p>0.05)$. Recreational runners do more low effort training sessions than elite athletes, the difference being insignificant $(\mathrm{t}=$ $0.378, \mathrm{p}>0.05)$. Recreational runners take more break days than elite athletes, the difference being insignificant $(\mathrm{t}=0.907, \mathrm{p}>0.05)$.

Table 9. Number of days dedicated to training depending on the type of effort and gender

\begin{tabular}{lll}
\hline & \multicolumn{1}{c}{ Gender } & Mean \\
\hline Sum High Effort & Men & 2.29 \\
& Women & 1.46 \\
Sum Medium Effort & Men & 1.53 \\
& Women & 2.02 \\
Sum Low Effort & Men & 1.47 \\
& Women & 1.34 \\
Sum Break & Men & 1.54 \\
& Women & 2.10 \\
\hline
\end{tabular}

Table 10. Number of days by age category depending on the type of effort

\begin{tabular}{lcccc}
\hline \multicolumn{1}{c}{ Age groups } & Sum High Effort & Sum Medium Effort & Sum Low Effort & Sum Break \\
\hline 35-44 years & 2.02 & 1.86 & 1.14 & 1.82 \\
45-54 years & 2.09 & 1.30 & 1.97 & 1.64 \\
55 years and over & 1.74 & 1.95 & 1.37 & 1.68 \\
\hline
\end{tabular}

Table 11. Number of days dedicated to training by elite and recreational athletes

\begin{tabular}{lcc}
\hline & Elite athlete/ Recreational runner & Mean \\
\hline Sum High Effort & Yes & 2.23 \\
& No & 1.88 \\
Sum Medium Effort & Yes & 1.90 \\
\multirow{3}{*}{ Sum Low Effort } & No & 1.64 \\
& Yes & 1.32 \\
Sum Break & No & 1.46 \\
& Yes & 1.55 \\
& No & 1.83 \\
\hline
\end{tabular}

\section{Discussion and Conclusion}

The self-determination theory claims that people have fundamental psychological needs and that well-being is important for personal development and integrity (Deci \& Ryan, 1985). When these needs are met, the person reaches a state of vitality (Van Dyck et al., 2017). 


\section{- Motivations for endurance running}

Until the age of 40, adults focus on achieving external goals, while after the age of 40, they turn their attention to internal goals. Theorists have found middle age to be characterised by major psychosocial changes in one's lifestyle and personality.

The changes in personality and lifestyle between the ages of 40 and 45 years are also caused by the midlife crisis, an identity crisis (second adolescence) generating a stressful period during which one's own existence is reassessed. The main stressors for this age group are due to family relationships, work, money and housing (Papalia et al., 2009). Probably the aforementioned aspects of adult life make some people engage in endurance running to find joy.

We classified the responses regarding motivations into the following categories: affiliation, well-being, recognition and health.

The research showed that most participants (67.2\% men and $66.7 \%$ women) were motivated by well-being (67\%). The second motivation was affiliation with other people (45.3\%), which was indicated by $46.9 \%$ of men and $42.9 \%$ of women. The third motivation was recognition (28.3\%), 32.8\% of men and $21.4 \%$ of women opting for it. These motivations were freely expressed by both men and women. The fourth motivation was health (19.8\%), which was highlighted by $17.2 \%$ of men and $23.8 \%$ of women.

No statistically significant differences between motivations for gender analysis were recorded, but women seemed to be more willing to run for health benefits. At the same time, there were no statistically significant differences between the motivations recorded for the analysis of elite athletes, who were more motivated than amateur runners.

Affiliation is the most important motivation for the 45-54 age segment and the least important for those over 55, with no significant differences in averages $(\mathrm{t}=1.42, \mathrm{p}>0.05)$.

Well-being is the most important motivation for all three age categories (35-44, 45-54, 55+), but one can observe the strictly increasing distribution with age, with significant differences between the first age category (35-44 years) and the last one (55 years and over) $(\mathrm{t}=2,776, \mathrm{p}$ $<0.01)$.

Recognition is the third motivation, being the most important for the first age category and the least important for the second category, without significant differences in averages $(t=$ $1.77, \mathrm{p}>0.05)$.

Health benefits are the last motivation of Masters athletes to run, being the most important for the 45-54 age category and the least important for the category of people aged 55 and over, without significant differences in averages $(\mathrm{t}=1.94, \mathrm{p}>0.05)$.

We agree with Doyenart et al. (2020) that there is a relationship between physical activity and mental health, the authors identifying an increase in the level of happiness $(25 \%)$ and selfesteem (40\%) after competition. By running, people (67\%) find well-being, an oasis of calm where they can escape from everyday life at least for a while.

We also agree with Nikolaidis et al. (2018) who say that, for Masters athletes, running is more about recreation and less about competitiveness. Our study has highlighted that Masters athletes are mainly motivated by a state of well-being.

In this literature review on how athletes' motivations were investigated, we noticed that the Motivations of Marathoners Scales (MOMS) was the most widely used tool (Masters et al., 1993). We wanted the study participants to freely express their motivations, athletes' responses 
being found in the MOMS (health, weight concern, self-esteem, meaning of life, psychological coping, affiliation, recognition, competition, personal goal achievement).

Although health exercise is actively promoted in Romania, Masters athletes are primarily looking for well-being in running. Their main motivations as identified in our study partially contradict the motivations found by Malchrowicz-Mośk and Poczta (2018), who list the following most important motivations of Masters athletes: fitness and good health, desire to test themselves and desire to develop a passion for running, all these being expressed by both men and women. This is explained by the fact that athletes run especially for their own general sense of well-being. The response can be found in stress.

Among the respondents, $47.7 \%$ also travelled abroad to participate in international events, and we agree with Poczta and Malchrowicz-Mośko (2018) who say that sports tourism is a necessity of modern times, a trend for sports enthusiasts. Thus, sport combines with tourism and health benefits in a very pleasant way.

Masters athletes mostly train for themselves in search of the well-being provided by running and favour half-marathon events due to the slower pace it requires (Nikolaidis et al., 2019). From a physiological and gerontological point of view, motor abilities decrease with age (Nikolaidis et al., 2019) but, through endurance running, Masters athletes are capable of outstanding athletic and physiological functional performance and represent a positive example of exceptional aging (Tanaka \& Seals, 2008).

Elite athletes with membership in a sports club (28\%) continue to practise running, which has become a way of life for them. All study participants reported that running has brought only positive changes in their lives.

\section{- Training}

Although the training programme of Masters athletes is limited because most of them are professionally active, $79.8 \%$ claim they easily combine training with their responsibilities and only $5.5 \%$ find it difficult to set aside time for training. Many want to train to improve their performance, to do research by themselves, but the information for the Masters category is insufficient and may not be the most accurate. Given that only the amount of training sessions was analysed in this study, we cannot comment on the quality of the training regimen. Athletes are clearly conscientious, as evidenced by the average of 13 years of practice and the continuation of this activity.

Each participant provided descriptions of their weekly training sessions using common terms (instead of sports terminology). Not everyone is endowed with the genetic and physical qualities, physiological and psychological traits of professional endurance runners. There are not many who train with qualified staff. Thus, $12.8 \%$ stated they had a coach, but the vast majority $(87.2 \%)$ trained using the information sought by themselves. Some want to get better at running and be competitive, while others just want to finish the race. Every athlete is unique.

Boullosa et al. (2020) show in their study that, despite the increasing popularity of halfmarathon running as a recreational activity for Masters athletes, there is no effective programme that presents best training practices so that Masters athletes can improve their performance while maintaining their health status and remaining injury-free. There are many training methods for endurance running that are not supported by evidence-based studies (Boullosa et al., 2020). Personal trainers (factual or virtual through state-of-the-art mobile 
applications) play an important role in the physical and mental training of athletes by using a motivating coaching style and providing positive feedback (Van Dyck et al., 2017).

In the life of an individual, there are several factors that have a negative impact on the state of well-being, causing discomfort. The sports environment is an ideal context for studying wellbeing and self-esteem. The research literature has shown that high levels of self-esteem are associated with psychological health and well-being, pressure control or anxiety (MuñozVillena et al., 2020).

Our behaviour and personality are influenced by our self-esteem. Motivations to practise endurance running at a more mature age result in a positive perception and a higher level of self-esteem and self-confidence. A strong "iceberg" personality (Nikolaidis et al., 2018) that is acquired through sport expands and provides benefits in other areas of the adult athlete's life.

In these modern and turbulent technological times, Romanians have realised that physical activity has a catalytic role in improving health naturally, that through the generated state of well-being, it can lead to an improvement in mental health (Za et al., 2020).

Sometimes, even the most motivated and dedicated runners can experience a decline in motivation. In this situation, they must try to maintain their motivation and eliminate all reasons for not running. They need to remember what their bodies have discovered by running, not only in terms of physical exercise but also in terms of mental health and increased self-esteem. Conscious stimulation of the mood, of the motivation to run is one of the solutions to succeed in practising this sports activity in the long run (Hufton et al., 2015).

In order to maintain good health and well-being, human biology requires a certain amount of physical activity. A physically active population is important both for the health of the individual and for society and thus sports participation is an increasingly important motivating factor for exercise. Competitive or non-competitive sports participation promotes healthy behaviour and a better quality of life. Training and exercise improve mood and stress coping, strengthening self-esteem and social skills (Malm et al., 2019).

The major strength of this study is that our sample consists of experienced amateur athletes (averaging 13 years of practice), who have deeply serious and important motivations for engaging in endurance running and almost nothing can prevent them from pursuing their hobby.

The end of the study showed that the experimental hypothesis was confirmed in practice, validating the initial assumptions on which our research was based. The motivational intention to practise endurance running is found in well-being, affiliation, prestige and health. Wellbeing-oriented motivations should be understood beyond the psychological aspects. Athletes take intentional and controlled risks in their workouts to have the highest possible well-being. Exploring the reasons why some people adhere to endurance effort, we have found that their motivations are extremely complex, playing a key role in maintaining the active lifestyle of individuals. Running can significantly improve well-being.

Masters athletes practise endurance running voluntarily, for their own enjoyment; they manage their personal activities so as to include training in their daily lives, which automatically offers them great motivation to exercise. Because running gives them so much pleasure, Masters athletes are not discouraged from training in either low or extremely high temperatures. They suffer when they cannot run (due to weather or health problems). Whenever 
they travel, regardless of the reason, Masters athletes always make room in their luggage for their running equipment and are constantly looking for places to run.

Despite alarming rumours that running is dangerous, it is said: the only mechanism ever discovered that can prolong life and prevent aging is exercise, given that there is no evidence that antioxidants, vitamins or anything else can prolong life (Cucuzzella, 2019).

From a practical point of view, this information could be interesting for promoting halfmarathon events because there is a desire to participate, interact and adopt an active and sportoriented lifestyle. Masters athletes can be role models for society because they are special people with good planning skills, who accept challenges and carry them beyond the finish line, as in a half-marathon event. If we study the evolution of Masters athletes, we notice that they grow older in a beautiful way, keep fit and are disciplined, so the other activities are beneficially influenced (Utzschneider, 2014).

Endurance running involves a lot of sacrifices in other areas of life for Masters athletes. Running is the ideal way to keep fit, enjoy health and well-being and be in harmony with yourself (Thurgood et al., 2014). For a motivated athlete, there is nothing more frustrating than not being able to run, being deprived of the feeling of satisfaction experienced after running!

\section{Limitations}

A major limitation of this research was the failure to use a scale to measure motivation. Another limitation was related to the assessment of athletes' training, as we mainly focused on the amount rather than the quality of weekly training sessions. Everyone explained their training regimen in their own words because they did not know the sports terminology, not being specialists in the field. A qualitative study of training programmes is needed.

The results obtained can only be indicative, they cannot be generalised due to the small size of our sample. No competitions took place in 2020, only virtual ones being allowed. Despite all these limitations, we can confidently say that a strong motivation to maintain increased selfesteem is what determines Masters athletes to perform aerobic training.

Even if your enthusiasm is not optimal and you are not in the mood for running but you still push yourself to train that day, your self-esteem will increase after the running session and you will feel mentally recovered.

\section{Acknowledgments}

We wish to give thanks to the participants who agreed to take part in our study.

\section{References}

Boullosa, D., Esteve-Lanao, J., Casado, A., Peyré-Tartaruga, L. A., Gomes da Rosa, R. G., \& Del Coso, J. (2020). Factors affecting training and physical performance in recreational endurance runner. Sports, 8(3), 2-20. https://doi.org/10.3390/sports8030035

Cucuzzella, M. (2019). Aleargă ca să trăiești bucuria și starea de bine prin mișcare [Run for your life: How to run, walk, and move without pain or injury and achieve a sense of wellbeing and joy]. Niculescu. 
Deci, E. L., \& Ryan, R. M. (1985). Intrinsic motivation and self-determination in human behavior. Plenum.

Doyenart, R., Olimpio, M., Boeira, D., Sombrio, F., Milhomes, Y. P., Gomes, K., Thiruphati A., \& Acordi da Silva, L. (2020). Psycho-physiological changes after a half marathon in amateur runners. Journal of Physical Education \& Sport, 20(4), 1768-1774. https://doi.org/10.7752/jpes.2020.04240

Dumitrescu, S. (2019). Alergăm pentru sănătate - Din tainele eforturilor fizice [We run for health - From the mysteries of physical exertion]. Editura pentru Sport.

Epuran, M., Holdevici, I., \& Tonița, F. (2008). Psihologia Sportului de Performanță. Teorie și practică. [Performance Sport Psychology. Theory and practice]. FEST.

Hufton, E., Pickering, E., \& Wadsworth, A. (2015). Enciclopedie practică ilustrată. Alergare, ciclism și fitness. [Complete practical encyclopaedia of running, cycling \& fitness training]. Aquila.

Malchrowicz-Mośko, E., \& Poczta, J. (2018). Running as a form of therapy sociopsychological functions of mass running events for men and women. International Journal of Environmental Research and Public Health, 15(10), 2-15. https://doi.org/10.3390/ijerph15102262

Malchrowicz-Mośko, E., Ploszaj, K., \& Firek, W. (2018). Citius, Altius, Fortius vs. slow sport: A new era of sustainable sport. International Journal of Environmental Research and Public Health, 15(11): 2414. https://doi.org/10.3390/ijerph15112414

Malchrowicz-Mośko, E., León-Guereño, P., Tapia-Serrano, M. A., Sánchez-Miguel, P. A., \& Waśkiewicz, Z. (2020). What encourages physically inactive people to start running? An analysis of motivations to participate in Parkrun and City Trail in Poland. Frontiers Public Health, 8: 581017, 1-9. https://doi.org/10.3389/fpubh.2020.581017

Malm, C., Jakobsson, J., \& Isaksson, A. (2019). Physical activity and sports - Real Health Benefits: A review with insight into the public health of Sweden. Sports, 7(5),127, 2-28. https://doi.org/10.3390/sports7050127

Masters, K. S., Ogles, B. M., \& Jolton, J. A. (1993). The development of an instrument to measure motivation for marathon running: The Motivations of Marathoners Scales (MOMS). Research Quarterly for Exercise and Sport, 64(2), 134-143. https://doi.org/10.1080/02701367.1993.10608790

Menheere, D., Janssen, M., Funk, M., Van der Spek, E., Lallemand, C., \& Vos S. (2020). Runner's perceptions of reasons to quit running: Influence of gender, age and runningrelated characteristics. International Journal of Environmental Research and Public Health, 17(17), 2-12. https://doi.org/10.3390/ijerph1717604/6

Muñoz-Villena, A. J., Gómez-López, M., \& González-Hernández, J. (2020). Perfectionism profiles and anger responses: The relevant role of self-esteem in athletes of professional quarries. International Journal of Environmental Research and Public Health, 17(4), 2-9. https://doi.org/10.3390/ijerph17041416

Nikolaidis, P. N., Cuk, I., \& Knechtle, B. (2019). Pacing of women and men in half-marathon and marathon races. Medicina, 55(1): 14. https://doi.org/10.3390/medicina55010014

Nikolaidis, P. T., Rosemann, T., \& Knechtle, B. (2018). A brief review of personality in marathon runners: The role of sex, age and performance level. Sports, 6(3), 2-7. https://doi.org/10.3390/sports6030099

Nikolaidis, P. T., Alvero-Cruz, J. R., Villiger, E., Rosemann, T., \& Knechtle, B. (2019). The age-related performance decline in marathon running: The paradigm of the Berlin Marathon. International Journal of Environmental Research and Public Health, 16(11), 2-12. https://doi.org/10.3390/ijerph16112022

Papalia, D. E., Olds, S. W., \& Feldman, R. D. (2009). Dezvoltarea umană [Human development]. Trei. 
Poczta, J., \& Malchrowicz-Mośko, E. (2018). Modern running events in sustainable development - More than just taking care of health and physical condition (Poznan Half Marathon case study). Sustainability, 10(7), 2-14. https://doi.org/10.3390/su10072145

Summers, J. J., Sargent, G. I., Levey, A. J., \& Murray, K. D. (1982). Middle-aged, non-elite marathon runners: A profile. Perceptual Motor Skills, 54(3), 963-969. https://doi.org/10.2466\%2Fpms.1982.54.3.963

Tanaka, H., \& Seals, D. R. (2008). Endurance exercise performance in Masters athletes: Ageassociated changes and underlying physiological mechanisms. Journal of Physiology, 586(1), 55-63. https://doi.org/10.1113/jphysiol.2007.141879

Thurgood, G., Sapstead, G., \& Stankiewicz, C. (2014). Alergare și maraton. Ghid pentru incepători și sportivi de performanță. [The complete running and marathon book]. Litera.

Utzschneider, C. (2014). Mastering running. Human Kinetics.

Van Dyck, D., Cardon, G., De Bourdeaudhuij, I., De Ridder, L., \& Willem, A. (2017). Who participates in running events? Socio-demographic characteristics, psychosocial factors and barriers as correlates of non-participation: A pilot study in Belgium. International Journal of Environmental Research and Public Health, 14(11), 2-14. https://doi.org/10.3390/ijerph14111315

Za, S., Menhas R. D. J., Mahmood, S., Karim, M., Sang, X., \& Weng, Y. (2020). Physical activity is a medicine for non-communicable diseases: A survey study regarding the perception of physical activity impact on health wellbeing. Risk Management and Healthcare Policy, 2020(13), 2949-2962. https://doi.org/10.2147/RMHP.S280339 